\title{
RETRACTED: Effect of the solid retention time in the obtention of polyhydroxyalkanoates [version 1; peer review: not peer
}

\section{reviewed]}

\author{
Rolando Calero (iD), Manuel Martínez (iD)2 \\ ${ }^{1}$ Facultad de Ciencias de la Ingenieria, Universidad Estatal Peninsula de Santa Elena, La Libertad, Santa Elena, EC240250, Ecuador \\ ${ }^{2}$ Centro de Geoquímica, Facultad de Ciencias, Universidad Central de Venezuela, Caracas, 1040, Venezuela
}

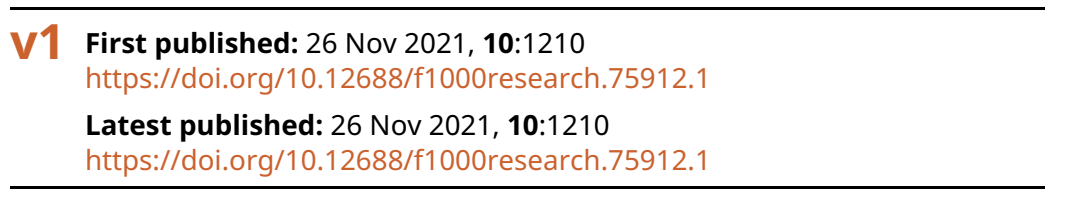

At the request of the authors, the article titled "Effect of the solid retention time in the obtention of polyhydroxyalkanoates" [version 1; peer review: awaiting peer review]. F1000Research 2021, 10:864 ( https://doi.org/10.12688/f1000research.28852.1) has been retracted from F1000Research.

Since publication of the article, the corresponding author has notified the Editorial team that this work was originally performed at University of A Coruña with the involvement of María C. Veiga and Christian Kennes, who were not notified regarding the submission of this manuscript or listed as authors. After discussion with all parties, including contact with the corresponding author's institution, it was agreed that the article would be retracted in order to correct the academic record. As the article contains content which potentially should not have been made publicly available the content of the article has been removed. The authors apologise for this honest error.

Keywords

Acidogenic fermentation, volatile fatty acids, polyhydroxyalkanoate, solids retention time

\section{Not Peer Reviewed \\ This article is an Retraction and has not been subject to external peer review.}

Any comments on the article can be found at the end of the article. 
Corresponding author: Rolando Calero (rcalero@upse.edu.ec)

Author roles: Calero R: Writing - Original Draft Preparation; Martínez M: Writing - Original Draft Preparation

Competing interests: No competing interests were disclosed.

Grant information: The author(s) declared that no grants were involved in supporting this work.

Copyright: (c) 2021 Calero R and Martínez M. This is an open access article distributed under the terms of the Creative Commons

Attribution License, which permits unrestricted use, distribution, and reproduction in any medium, provided the original work is properly cited.

How to cite this article: Calero R and Martínez M. RETRACTED: Effect of the solid retention time in the obtention of polyhydroxyalkanoates [version 1; peer review: not peer reviewed] F1000Research 2021, 10:1210

https://doi.org/10.12688/f1000research.75912.1

First published: 26 Nov 2021, 10:1210 https://doi.org/10.12688/f1000research.75912.1 